\title{
The First Billroth II Gastric Resection as Reported by an Italian Medical Journal
}

Nicolò Nicoli Aldini

\section{Summary}

A report on the first Billroth II surgical intervention for gastric cancer is entirely reprinted. The description is original and is taken from a letter published by a young Italian physician, Eugenio Casati, who was present in the operative theatre of the Second Surgical Clinic of the University of Vienna on January 15,1885 , while he was on a scientific journey in Europe. A biographical profile of the writer is provided. The origin of the surgical procedure for gastric resection known as Billroth II is also examined, and its significance in the early surgery of the alimentary tract is highlighted. A short account by Billroth's pupil, Viktor von Hacker, on the same intervention also allows comparison and a better knowledge of Billroth's surgical strategy in performing one of the starting points of modern gastric surgery.

The centenary of Theodor Billroth's death fell on February 6, 1994. On the occasions of previous significant anniversaries of the life of this outstanding surgeon (1829-1894), memorial studies were published ${ }^{1,2,3}$ and original documents concerning his life and his scientific activities were reviewed and published $^{4}$.

1 Absolon K.B.: Theodor Billroth's formative years. A Study in Memory of the Subject's 150th Birthday. American Journal of Surgery 137: 394-407, 1979.

2 Roses F.D.: On the Sesquicentennial of Theodore Billroth. American Journal of Surgery 138: 704-709, 1979.

3 Rutledge R.H.: In commemoration of Theodor Billroth on the 150th anniversary of his birth. Surgery 86(5): 672-693, 1979.

4 Schein C.J., Koch E.: Mikulicz's obituitary of Theodor Billroth. Surgery, Gynecology and Obstetrics 148: 252-258, 1979.

Dr. Nicolò Nicoli Aldini, Via Cincinnato Baruzzi 2, I-40138 Bologna, Italy 
As observed by Schein, "the personality of Billroth comes to us in at least two ways: there is an extensive collection of his personal letters published by Fisher" that is "a sort of personal diary"; the second source of knowledge "comes from statements about him written by his colleagues and students"

In order to offer a further contribution to the already rich documentation of the activity of this surgeon, we present a report about the first operation for gastric cancer, later known as Billroth II, as it was written by a young Italian physician who witnessed it in 1885 . There are two main points of interest in this report: first, it is an exact and detailed representation of the operative scene as it remained engraved in the mind of a thorough observer; second, it was published in a local Italian medical journal which ceased its activity at the beginning of 20th century, thus making it now a scarcely known, almost forgotten document.

The name of the young physician was Eugenio Casati, and the journal was the "Raccoglitore Medico" ["Medical Collection"]. First of all, let us introduce some information about the journal, the author, and circumstances that led to the publication of this report.

The writer's father, Luigi Casati, head surgeon in the City Hospital of Forlì, in the province of Romagna, was "of great benefit to surgery.... because of his promptness and precision in relating progress in the "Raccoglitore Medico", a journal of his own and which he edited" 6 . This medical journal started its activity in 1838 in Fano, a small provincial town near Ancona, and ceased publication in 1905. Casati became editor in $1862^{7}$ and preserved "that practical approach .... and that rational adhesion to the continuous progress of our science" which characterized the journal.

When his son Eugenio set off on a scientific tour of Europe a few months after his graduation, Casati published the son's medical letters in the journal. In the foreword of the January 1884 issue he presented the new contributors by writing: "the other [contributor] is my son Eugenio, who is attending his post-graduate courses in the hospitals of Berlin, from where he will send his monthly scientific correspondence".

Eugenio Casati was born in 1859. He obtained his degree in medicine in 1883 at the University of Florence. A few months later, in December of the same year, he started his journey of 20 months through Germany, Austria and

5 Schein (n. 4).

6 Nigrisoli B.: Chirurghi e Chirurgia della Romagna sul finire dell'Ottocento (1890-1896). La Piê (Forlì) XX (4-5): 71-76, 1947.

7 Ravaglia G.: In memoria del comm. Luigi Casati. Bullettino delle Scienze Mediche (Bologna) VI: 667-668, 1906.

8 Casati L.: Ai Lettori. Raccoglitore Medico XXI: 3-5, 1884.

9 Casati (n. 8). 
France. At that time, according to Nuland, the great University Hospitals of Germanic countries were the most advanced in the world for medical science. Therefore, in the second half of the 19th century and until World War I these institutions were models of medical progress and education, causing young doctors from many parts of the world to move to Germany, Austria, Switzerland for reasons of study ${ }^{10}$. The observations of Casati, who also worked in Virchow's Institute of Pathologic Anatomy and in Koch's Bacteriology Institute in Berlin ${ }^{11}$, were contained in fifteen letters issued monthly in the "Raccoglitore Medico", and later were collected in a single volume, published in $1885^{12}$. The letters give us not only an interesting idea of the Berlin, Vienna and Paris hospitals as they were observed by a young physician, but they also shed light on the author's personality. Casati appears to have had a sound medical education which exceeded the basic university training and was based on an up-to-date knowledge of the medical literature of his time in addition to a great capacity for synthesis, criticism and judgement. He was a young travelling physician, who made best use of the greatest hospitals of his time and contacts with the best of the medical world. Upon returning to his country, Casati became Professor of Gynaecology in 1888 and from 1892 to 1925 was Head of the Surgical Department of the Arcispedale S. Anna in Ferrara. In his curriculum vitae, more than 15,000 operations are recorded, 2,500 of which were laparotomies. He was also the author of 86 scientific papers, the most significant being those on gynaecological and alimentary tract surgery ${ }^{13}$. He died in 1944 in Portomaggiore, near Ferrara.

The reports from Vienna began in September 1884. In his letter dated October 28, Casati starts to describe Billroth's Hospital which "offers such a rich material that I can spend all my time with the simple report of what I have seen, there not having been a day in which at least 5 new patients were presented, always for major surgery" (Letter IX). With regard to this, Nuland confirms that among the numerous medical attractions of Vienna, the most celebrated was the Head of the Second Surgical Clinic of the University, Professor Theodor Billroth ${ }^{14}$.

E. R. Wiese remarks that the didactic talent of Billroth "made him one of the greatest teachers, not only of his time, but of all time". Indeed "the method of teaching was unique for that day. The cases were shown, the history and the reasons for operation were freely discussed from every angle. Never was

10 Nuland S. B.: I figli di Ippocrate. Milano, Mondadori ed., 1992.

11 Casati E.: Mio Curriculum Vitae 1883-1925. Ferrara, Stab. Tipografico Estense, 1925.

12 Casati E.: Lettere a suo Padre (Pubblicate sul Raccoglitore Medico negli anni 1884-85). Forlì,

Tip. Lit. Democratica, 1885.

13 Casati (n. 11).

14 Nuland (n. 10). 
the viewpoint of the patient ignored .... [Billroth] usually lectured during the operation"15. Rutledge agrees with this outline:"A typical Billroth lecture demonstration began with a case history presentation followed by a discussion of the differential diagnosis. Then Billroth performed the actual operation concluding by personally applying the patient's dressing .... He finished by summarizing the case and giving an overview of the entire subject"16.

Casati tried to communicate to his readers that which he had "the fortune to see and listen to every day" (Letter XI) dwelling on many orthopaedic, pediatric and gynaecological problems as well as on the new antisepsis and dressing techniques. On January 15, 1885 Casati realized that he had witnessed a truly new event, and informed his father of it by adding a post-scriptum to his monthly letter instead of waiting for his February letter. This, because he thought "it would be useful for you to obtain this information promptly" (Letter XI). The description of the operation is the most detailed one among those contained in the correspondence, and it is hereafter reported in full.

\section{From the letter XI of January 20, 1885}

"Billroth has enriched surgery with a new operation which I am eager to describe to you, down to the last detail, to the best of my ability. It is a resection of the stomach and duodenum up to the choledochus, combined with a gastro-enterostomy. Although in the monograph by Wölfler, published in our Journal and translated by Usiglio, Billroth has already mentioned the feasibility of such an operation in the case of a widespread stomach neoplasm, it had not yet been performed, and I thought it would be useful for you to be promptly informed of it. In the morning of January 15, a patient with a large abdominal mass was brought in. Objective and subjective symptoms suggested a gastric cancer involving the pyloric region. A preoperative diagnosis on the extension of the tumour being impossible when preparing for the operation, Billroth was in doubt to perform a gastric resection or a simple gastro-enterostomy.

Below the ensiform appendix and a little towards the right he made an almost entirely longitudinal incision of $15 \mathrm{~cm}$ along the length of the tumour. He thus opened the peritoneal cavity carrying out a complete hemostasis of the cut surface with forceps and ligatures. After the ligature of the large vessels he cut the great omentum, laying the stomach bare and immediately pulling it out of the abdominal cavity. At that stage one could see that the tumour was isolated but spread over the greater curvature, the lesser curvature, and the first part of the duodenum. This made the resection of the stomach and the connection of the duodenum to either the greater or the lesser curvature impossible. Billroth, without hesitation started this new intervention. While keeping the stomach out of the wound he searched for the distal part of the

15 Wiese E.R.:Theodore Billroth Scholar, Musician, Master Surgeon. Annals of Medical History X (3): 278-286, 1928.

16 Rutledge (n. 3). 
duodenum, which he also pulled out. Then he performed a transverse incision of $5 \mathrm{~cm}$ on the great curvature of the stomach, some centimeters from the left margin of the tumour, thus opening the cavity of the stomach. Exactly the same incision as that on the stomach was made on the upper margin of the end of the duodenum. Obviously, great care was taken to avoid the effusion of the contents of the stomach and of the duodenum from the incisions which were kept closed by the assistant surgeon.

At this stage he began the suture, starting, of course, posteriorly. He joined together the corresponding surfaces of the two previous incisions, and reunited the serosae of the stomach and bowel with a Lembert's suture. In the posterior part of this circular suture, where the mucous membrane is abundant, Billroth placed some stitches between the two mucosae. When he concluded this first procedure, he had made a communication of the stomach with the distal part of the duodenum, or rather with the proximal part of the ileum [sic!]. Then he started the second part of the operation, namely the resection of the stomach and the duodenum. Before that, he freed the stomach from all the adherences and ligaments, tying them with a large thread, and then cutting them with a Paquelin's thermocautery. To avoid any lesion produced by the thermocautery, he placed a pair of flat scissors under the adherence and cut the tissue, pressing it between the scissors and the thermocautery.

After entirely separating the stomach, and preventing bleeding by using clamps, he resected the duodenum below the end of the neoplasm. This resection was performed as extensively as possible, until he had almost reached the choledochus, which of course he could not go beyond. This detachment was performed by first cutting transversally the duodenum with a scalpel. After making an opening in the duodenum, he introduced a sponge with a thread into the lower part of it. Then, using the scissors, he carried out a circular detachment of the tumour. Subsequently, he closed the distal end of the duodenum with Lembert's stitches, after removing, of course, the sponge. At this point Billroth started the detachment of the tumour from the stomach. He performed an incision on the posterior and anterior wall, by beginning almost at the point where he had connected the intestinal loop, i.e. the gastro-enterostomy. With the scissors he dilated the incision for some centimeters, and immediately closed it with a Lembert's suture connecting the posterior and anterior walls of the stomach.

Then he proceeded with the removal of the tumour, carefully suturing as the work advanced. So, through four stages he obtained the complete detachment of the tumour. At this point he carefully examined the former sutures, using other threads when the contact between the two surfaces appeared loose. I also must tell you that Billroth took care that on the right side, where the suture of gastro-enterostomy ended and the rising suture of the stomach started, there was no angle, but a curve. This was done to avoid the formation of any diverticule and the retention of food, the consequences of which had caused the death of Billroth's first patient.

When the operation was over, he sutured the abdominal wall in three layers. In the first layer he included the parietal peritoneum and the extraperitoneal connective tissue; in the second muscles; in the third the skin and subcutaneous connective tissue. He then inserted a large drain, which didn't, however, enter the peritoneal cavity, but remained between the muscles and the peritoneum, and applied dressing.

The operation, including the dressing, lasted about an hour and half. But to complete the description of this daring operation, I must tell you that in addition to the cul-de-sac a little part of the two curvatures of the stomach was also preserved. It is easy to understand how the bile can reach the point where it mixes with the food be- 
cause of this kind of gastro-enterostomy. From the choledochus the bile is discharged into the remaining part of the duodenum. It travels past this point and, with simple peristaltic movements, it can pass through the third part, even if that is not only transverse but also has an ascending direction, because it was joined to the greater curvature of the stomach at the proximal part of the ileum [sic!]. As we can see, therefore, the bile is not removed but remains available for food digestion, and this is of great importance. I think I have given a rather exact idea of the procedure followed by Billroth for this new operation. It is important to add that the patient on postoperative day 6th was well, and never had the slightest increase of temperature, or any pain. He was on the road to recovery, then, and the advisability and benefit of such surgery were clearly demonstrated by the regular drainage of the bile. With respect to the final result of this very interesting case, I will keep you informed.

Vienna, January 20th, 1885."

\section{Casati's report: a survey}

As above mentioned, this report is the most detailed among those contained in Casati's letters. This demonstrates not only the importance that he ascribed to what he was seeing, but also his capacity to retain the observations and to relate them in a logical fashion. The description is clear and lively, so the reader becomes a spectator as if he were present in the operating theatre. It is interesting to note in this report some particular aspects of Billroth's behaviour also noticed by other authors: his confidence and speed on the operating table (Billroth always operated with the same assuring calm, and what is of no less importance, quickly [Mickulicz] $)^{17}$; the accuracy in hemostasis (impressed me chiefly .... the great number of artery forceps used [Halsted] ${ }^{18}$; the care in personally applying also the final dressing to the patient (performed the actual operation, concluding by personally applying the patient's dressing $)^{19}$.

In 1885 Viktor von Hacker (1852-1933), another of Billroth's pupils, published a short account on this operation in a paper devoted to a statistical survey on clinical cases of gastric resection and gastroenterostomy ${ }^{20}$. A comparison between the two reports offers some points of interest. Indeed, by reading Von Hacker's paper we learn the age of the patient (48 years), the dimension of the tumour (large as a fist), and the exact duration of the operation ( $1 \mathrm{hr} .45 \mathrm{~min}$.). There is a fair agreement between the two reports, even if that of Von Hacker is much more synthetic and describes only the basic

17 Schein (n. 4).

18 Roses (n. 2).

19 Rutledge (n. 3).

20 Von Hacker V.: Zur Casuistik und Statistik der Magenresectionen und Gastroenterostomieen. Archiv für Klinische Chirurgie XXXII (3): 616-625, 1885. 
procedures of the surgery. To allow a comparison between the two papers, Von Hacker's report is translated in the Note.

To complete this survey on Casati's report, we must nevertheless consider also some of the writer's innaccuracies: the most important is the improper use of the term "ileum" instead of jejunum when he described the accomplishment of the gastroenterostomy. Another imprecision is when Casati names the patient who died because of the formation of a diverticule on the gastric stump after resection. According to the clinical case histories of the early gastric resections of Billroth (Billroth I), issued by Wölfler ${ }^{21}$ and quoted below, this event did not occur in the first but in the second patient, a woman operated on February 28, 1881.

\section{From Billroth I to Billroth II}

Casati's letter also gives us the opportunity for some consideration on the development of gastric surgery in Billroth's clinic between 1881 and 1885 .

The early history of gastric resection, with the unfavourable efforts of Péan (1879) and Rydyger (1880) and the experimental investigations that in 1881 led to the first successful operation, are detailed in Wölfler's issue "Über die von Herrn Prof. Billroth ausgeführten Resectionen des karcinomatösen Pylorus"22. After the resection of the stomach, Billroth anastomosed the duodenum to the gastric stump, thus pioneering the procedure that is known as Billroth I. Casati in his letter made reference to this monographic study as translated into Italian by the surgeon Gustavo Usiglio ${ }^{23}$ who at the time was in Billroth's clinic as a resident.

Anton Wölfler (1850-1917), a pupil of Billroth in the Surgical Clinic of the University of Vienna, later became Professor of Surgery in Graz and Prague $^{24}$. In his monographic work he mentioned that the experiments on dogs, performed by two of Billroth's other pupils, Carl Gussenbauer (1842-1903) and Alexander von Winiwarter (1848-1917), led to the early clinical attempts. They addressed their investigations to the evaluation of the physiopathological and surgical bases of gastric resection, and Billroth acknowledged his co-workers after the first operation declaring: "please forgive

21 Wölfler A.: Über die von Herrn Prof. Billroth ausgeführten Resectionen des karcinomatösen Pylorus. Wien, W. Braunmüller, 1881.

22 Wölfler (n. 21).

23 Usiglio G.: Resezioni del piloro per carcinoma per Antonio dott. Wölfler, medico assistente nella Clinica Chirurgica del Prof. Billroth e docente di Chirurgia nella Università di Vienna. (Traduzione). Raccoglitore Medico XVI: 193-225 and 241-274, 1881.

24 Absolon K.B.: The surgical school of Theodor Billroth. Surgery 50(4): 697-715, 1961. 
me if I have a certain pride in the work of my pupils which made this progress possible"25. In Wölfler's monographic work the first five cases were also described, with their progressive technical modifications to achieve better results, and with their postoperative course. A 43-year-old woman was the first patient who underwent the operation on January 29,1881 . She survived 4 months, and died from metastases. One month later, a second operation on a 32-year-old woman had an unfavourable result and the patient died on the eighth postoperative day after a re-operation for an obstructive complication. This is the case considered in Casati's report and erroneously indicated as "the first Billroth patient".

Reading Wölfler's paper, we realize that the need for further improvements of this technique was quite clear to the author as well as to the entire Billroth staff. "We are neverthless persuaded", stated Wölfler, "that this intervention, now in the early stages of its development, will be submitted in a short time to various appropriate improvements. The considerations which we will make about the surgical procedure, which at present appears the most suitable, may in a short time be replaced by better operative methods" ${ }^{\text {" }}$. This pathway was also suggested by Billroth himself: "The objective of further studies has to be the indications and contraindications and the techniques for different cases" 27 .

Between 1881 and 1885 experimental investigations on animals were performed again. In 1883, at the Twelfth Congress of the Association of German Surgeons, Wölfler presented a canine model upon which a gastro-jejunostomy with a distal end-to-side jejuno-jejunostomy was carried out ${ }^{28}$.

The extent of the neoplasm was one of the technical problems: "if after an excessively wide excision the stomach cannot be approached and reunited to the duodenum .... the only course is to suture the entire lumen of the stomach and to establish a duodenal fistula for the nutrition" suggests Wölfler ${ }^{29}$. This statement shows that in 1881 , immediately after the early surgical successes, a more rudimentary way to resolve this fundamental matter was proposed than that accomplished a few years later. However, the guidelines for a solution to the problem were by then clear in Billroth's mind. In his paper "Zur Casuistik und Statistik der Magenresectionen und Gastroenterostomieen" published in 1885, von Hacker observed: "In his lectures Professor Billroth repeatedly gave the idea that in pyloric cancer which is widespread on the

25 Roses (n. 2).

26 Wölfler (n. 21).

27 Roses (n. 2).

28 Vauthey J.N., Maddern G.J., Gertsch P.: César Roux - Swiss pioneer in surgery. Surgery 112(5): 946-950, 1992.

29 Wölfler (n. 21). 
great and the lesser curvature, making it impossible to rejoin the duodenum with the stomach, or risking substantial tension in the suture after an extensive resection, one should resect the affected part .... and join the stomach and jejunum using Wölfler's gastro-enterostomy" ${ }^{30}$.

In 1881 Anton Wölfler had accomplished the first successful antecolic gastroenterostomy on a patient with inoperable pyloric cancer ${ }^{31}$. The patient survived for four months. Palliative surgery was becoming a current practice in the management of oncological patients.

Thus, in 1881, the foundations were already in place for further surgical developments: the Billroth II procedure (Tab.1) arises from the combination of an exeresis (as in Billroth I, but wider) and a reconstruction (Wölfler's gastroenterostomy).

The reading of von Hacker's paper gives us an exact explanation of Billroth's surgical strategy which Casati, as a simple observer, probably did not notice. It confirms the synthesis between Wölfler's gastroenterostomy and the Billroth I resection performed on a weakened and critically ill patient. "Because of the patient being in a critical condition", wrote von Hacker, "Professor Billroth performed at first gastroenterostomy, to be sure of controlling the situation even if dangerous symptoms did occur. Gastroenterostomy was carried out according to Wölfler's method, the jejunum was superposed to the transverse colon and fixed to the stomach. After this, due to the speed at which the operation was carried out, the patient did not collapse, and the pulse was strong; therefore, the excision of the neoplasm was thus started".

Thus, an appropriate patient, a prepared mind, and a prudent behaviour provided the opportunity for this first attempt that was afterwards and until now named with the eponym of Billroth II. The prudent behaviour of Billroth in the operating theatre was coherent with his thought that one must operate only when there is some chance of success ${ }^{32}$.

Three fundamental steps, as found in Casati's report, are the true Billroth II ways to gastric resection ${ }^{33}: 1$ ) the creation of an antecolic latero-lateral gastro-entero anastomosis; 2) the detachment of the stomach from the duodenum beyond the pylorus; 3 ) the resection of the stomach and the closure of the duodenal and gastric stumps (Fig. 1). The termino-lateral anastomosis between the gastric stump and the jejunum represents a modification already suggested in 1885 by von Hacker, practiced by Krönlein (1887) and von Eiselberg (1888), and later improved in different ways by Reichel, Polya, Hof-

30 Von Hacker (n. 20).

31 Wölfler A.: Gastro-enterostomie. Centralblatt für Chirurgie 45: 705-708, 1881.

32 Sigerist H.E.: Los grandes Médicos. Historia biografica de la medicina. Ediciones Ave, Barcelona, 1949.

33 Schmieden V., Fisher A.W., Uffreduzzi O.: Operazioni Chirurgiche. Torino, U.T.E.T., 1938. 
Tab.1.Development in surgical treatment of gastric cancer in Billroth's clinic from 1881 to 1885

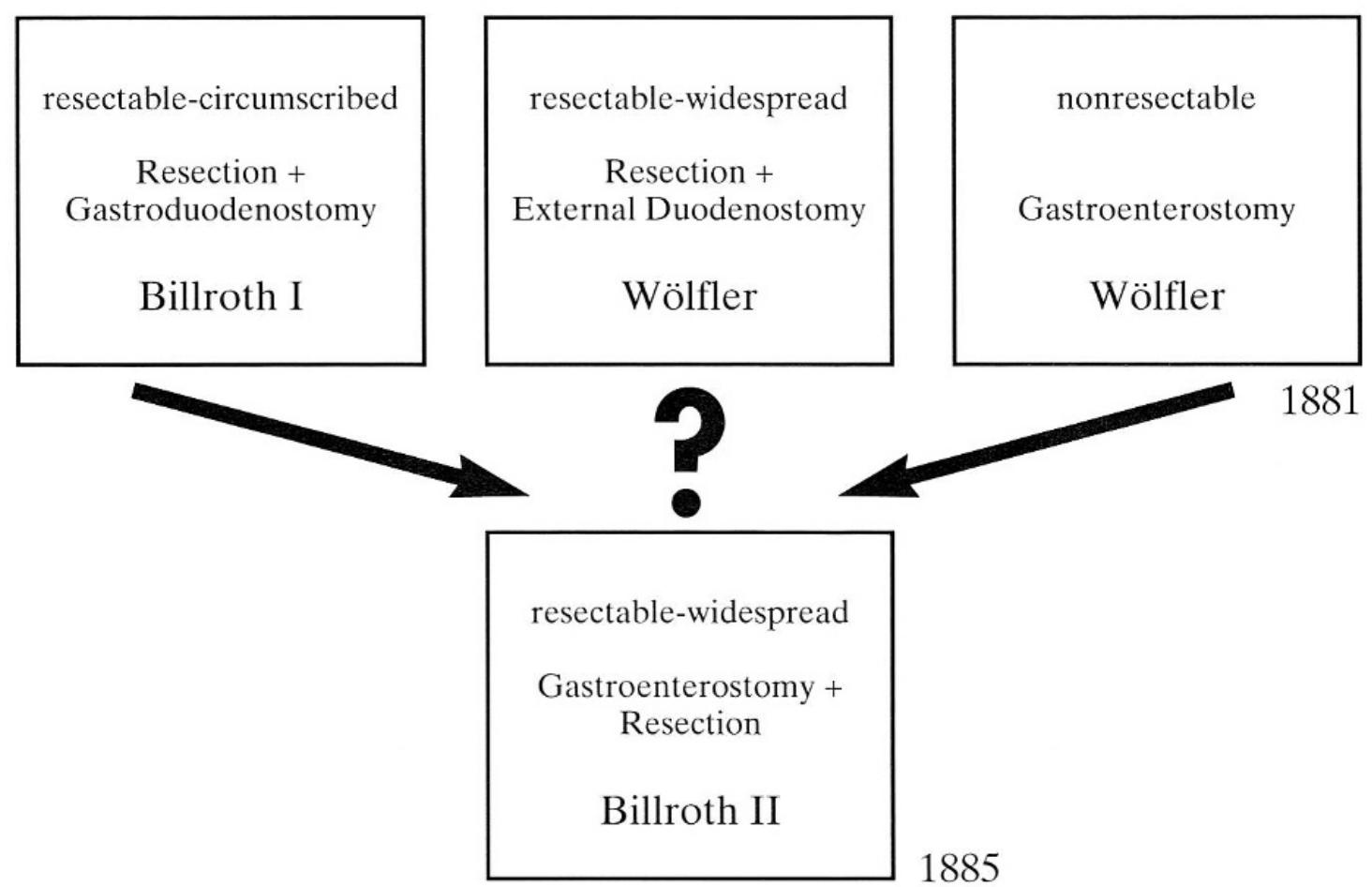

meister, Finsterer and other surgeons based upon the original way traced by Billroth ${ }^{34}$.

The postoperative course of the patient was favourable. "The patient is very well, has increased his weight, and his appearance is very much better. The food, however, is always liquid, because once when Billroth tried to feed him solid food he had a bad stomach-ache. The bowel functions are very good, and now not only is the feasibility of this operation demonstrated, but it is also shown that even if Billroth does not save the life of this man with this difficult operation, he has surely prolonged it", related Casati one month later, in February's correspondence (letter XII). The last consideration also summarizes the realistic opinion of Billroth about the results of his surgery. After the first gastric resection in 1881 he indeed wrote "I hope we took a good step in the right direction to cure some of the unfortunates who have been thought to be incurable so far, or at least to alleviate the pain of those who finally will succumb to carcinoma and its metastases" 35 .

In his account von Hacker indeed points out that six weeks after the operation "hardening in the epigastric region was observed, and the recurrence

34 Kleinschmidt O.: Zur Geschichte des Billroth II. Der Chirurg 1:631-633, 1929, and Späth F., Kronberger L.: Der antecolische B II und seine Geschichte. Wiener Klinische Wochenschrift 75 (41-42): 715-718, 1963.

35 Roses (n. 2). 


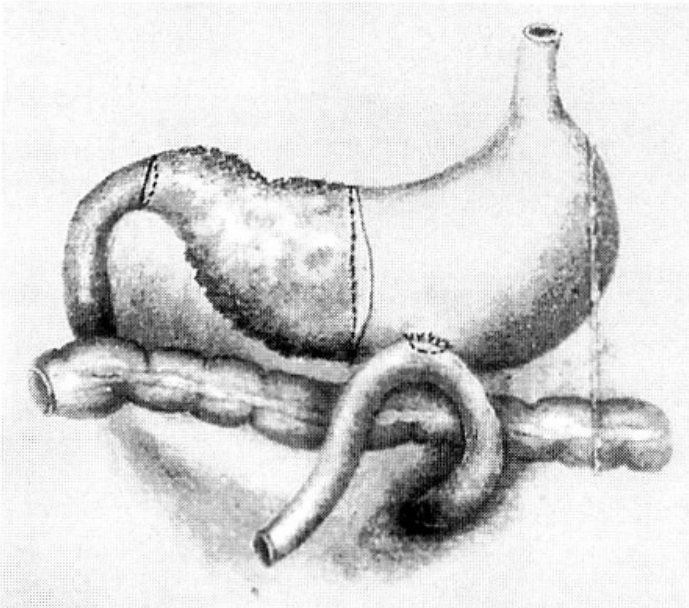

a

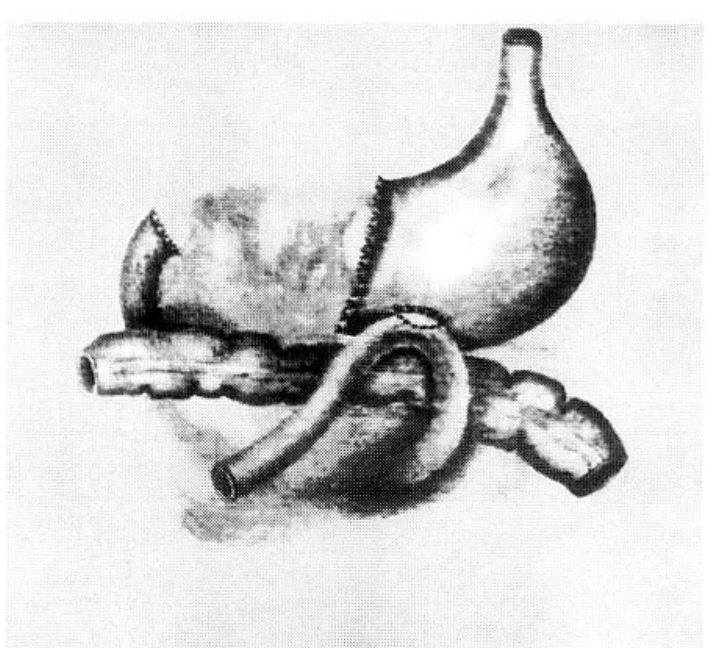

b

Fig. 1. Drawings from the paper of Viktor von Hacker "Zur Casuistik und Statistik der Magenresectionen und Gastroenterostomieen" that show the Billroth II procedure for gastric resection:

a) an antecolic latero-lateral gastro-entero anastomosis is performed before the excision of the carcinomatous pylorus;

b) the resection of the stomach follows, with the definitive closure of the gastric and duodenal stumps.

of neoplasm was suspected" ${ }^{36}$, thus suggesting a bad prognosis for the patient.

In the same year 1885 in which Billroth had accomplished this new surgical procedure, he stated that "he who combines the knowledge of physiology and surgery, with the artistic side of his subject, reaches the highest ideal in medicine" ${ }^{137}$. In those days, surgical physiopathology appears on the threshold of the operating theatre as a new rational way to approach patient management. Rutledge asserts that Billroth I is "Billroth's most significant technical achievement" ${ }^{38}$. This is perhaps true, but Billroth II is no less significant, and not only because it increased the chances for the surgeon and the patient. Indeed in 1881, when Billroth performed his first gastric resection, he still operated following an anatomical guideline, and restored the continuity of the alimentary tract by connecting the gastric stump and the duodenum. In 1885, when he anastomosed the stomach and jejunum for the same purpose, he carried out a reconstructive procedure which was merely functional, and the digestive process was now achieved by modifying the course of the gastrointestinal tract. From this perspective not only Billroth I but also Billroth II was 
an "epoch making resection" 39 . A deep conceptual difference between the two techniques exists with respect to the restoration of function according to digestive physiopathology. Billroth II was the forerunner of a new way in surgery, in which anatomy and function were separated and function was preserved on account of major anatomical changes. Casati was therefore the witness to one of the starting points of modern surgery of the digestive tract.

As many of Billroth's pupils (i.e. Czerny, Wölfler, Mickulikz, von Eiselberg) became the heads of some of the leading surgical schools of Europe ${ }^{40}$, the techniques pioneered between 1881 and 1885 and further improved in the following years, were to become the foundations of gastric surgery. According to Lesky, who quotes von Habner, "Billroth and his pupils initially set up all the methods .... by which we treat all the gastric and duodenal diseases" $"$.

When Billroth died on February 6, 1894 in Abbazia on the coast of Istria, he had already seen the great expansion of his school, and he had felt that "the greatest happiness of my life was founding a school that carries on my aims of scientific and humanitarian accomplishments" ${ }^{42}$. However, it was too early to appreciate the wide popularity that his technical achievements would gain in the subsequent century among surgeons all over the world.

"The physician, like the artist, must constantly produce and reproduce"43. Stating this thought in 1875 , and writing to his friend, Johannes Brahms, that "science and art spring from the same source"44, Billroth had outlined the true nature of his own personality, which had already made him noteworthy in the eyes of his contemporaries.

\section{Note}

To allow comparison between the report of Eugenio Casati and that of Viktor von Hacker we have translated from his paper "Zur Casuistik und Statistik der Magenresectionen und Gastroenterostomieen" ${ }^{45}$ the part in which the operation is described:

39 Schein (n. 4).

40 Absolon (n. 24).

41 Lesky E.: Die Wiener Medizinische Schule im 19 Jahrundert. Verlag Hermann Bohlaus Nachf./,Graz-Köln, 1965.

42 Absolon (n. 24).

43 Billroth T.: The Medical Sciences in the German University: A Study in the History of Civilization (translated by Welch WM). New York, Mc Millan, 1924.

44 Roses (n. 2).

45 Von Hacker (n. 20). 
"There was a 48-years-old man presenting the symptoms of a pyloric stenosis from a carcinoma. Opening the abdomen, a tumor large as a fist was found, which was very movable and not circumscribed; it was expecially spread out on the greater curvature. Because of the patient being in a critical condition, Professor Billroth performed at first gastroenterostomy, to be sure of controlling the situation even if dangerous symptoms did occur. Gastroenterostomy was carried out according to Wölfler's method; the jejunum was superposed to the transverse colon and fixed to the stomach. After this, due to the speed at which the operation was carried out, the patient did not collapse, and the pulse was good; therefore the excision of the neoplasm was started. The tumor was isolated according to the usual technique on the lesser and greater curvature while the duodenum was manually compressed by the assistant; after that, the duodenal wall was folded up into the lumen, and closed in two layers with a Lembert's suture. The stomach was opened and immediately cleaned with a sponge; another sponge was introduced into the part to be resected. Then followed the resection of the stomach and the immediate suture with Lembert's stitches. The stomach [during this procedure] was also closed with manual compression. During the resection it was evident that the incision must be carried out towards the bottom of the greater curvature, beyond the tumour, to within $1 / 2 \mathrm{~cm}$ of the seat of the fistula between the stomach and the small bowel, because here the surface of the incision did not appear infiltrated by the tumour. The operation, including the closure of the abdominal wall, required $1 \mathrm{hr} .45$ min."

\section{Acknowledgements}

The author expresses his gratitude to Dr. Piero Bertocchi for his bibliographic advice and to Dr. Rinaldo Nicoli Aldini and Dr. Maria Luisa Nicoli Aldini Camadini for their assistance in translating the sources from German language. 